\title{
Article \\ Characterization of Properties of Soil-Rock Mixture Prepared by the Laboratory Vibration Compaction Method
}

\author{
Xiaoping Ji ${ }^{1, *} \mathbb{C}$, Honglei Lu ${ }^{1}$, Cong Dai ${ }^{2}$, Yonggen $\mathrm{Ye}^{3}$, Zhifei Cui ${ }^{1}$ and Yue Xiong ${ }^{4}$ \\ 1 School of Highway, Chang'an University, Xi'an 710064, China; 2020121175@chd.edu.cn (H.L.); \\ 2018221126@chd.edu.cn (Z.C.) \\ 2 Institute of Transportation Development Strategy \& Planning of Sichuan Province, Chengdu 610041, China; \\ daicongjky@163.com \\ 3 Hangzhou Ecological and Environmental Monitoring Center of Zhejiang Province, Hangzhou 310007, China; \\ yyg202@163.com \\ 4 Engineering Department, China Highway Engineering Consultants Corporation, Beijing 100089, China; \\ dxz9697@163.com \\ * Correspondence: jixp@chd.edu.cn; Tel.: +86-137-5994-7014
}

Citation: Ji, X.; Lu, H.; Dai, C.; Ye, Y.; Cui, Z.; Xiong, Y. Characterization of Properties of Soil-Rock Mixture Prepared by the Laboratory Vibration Compaction Method. Sustainability 2021, 13, 11239. https://doi.org/ $10.3390 /$ su132011239

Academic Editor: Rui Micaelo

Received: 1 August 2021

Accepted: 27 September 2021

Published: 12 October 2021

Publisher's Note: MDPI stays neutral with regard to jurisdictional claims in published maps and institutional affiliations.

Copyright: (c) 2021 by the authors. Licensee MDPI, Basel, Switzerland. This article is an open access article distributed under the terms and conditions of the Creative Commons Attribution (CC BY) license (https:// creativecommons.org/licenses/by/ $4.0 /)$.

\begin{abstract}
This paper presents a study of the properties of soil-rock mixtures (SRM) prepared by the vibration compaction method. First, the results of laboratory experiments and field tests are compared to determine the reasonable parameters of the vibration compaction method (VCM) for soil-rock mixtures. The compaction characteristics, CBR, and resilient modulus of the laboratory-prepared soilrock mixtures by the static pressure compaction method (SPCM) and vibration compaction method are compared. The effects of the soil to rock ratio and the maximum particle size and gradation on the compaction characteristic, resilient modulus and CBR of soil-rock mixtures prepared by the vibration compaction method are investigated. Finally, field measurements are subsequently conducted to validate the laboratory investigations. The results show that the reasonable vibration frequency, exciting force, and static surface pressure of the vibration compactor for soil-rock mixtures are recommended as $25 \mathrm{~Hz}, 5.3 \mathrm{kN}$, and 154.0 163.2 kPa, respectively. Soil-rock mixtures prepared by vibration compaction method has smaller optimum water content and gradation variation and larger density than specimens prepared by the static pressure compaction method, and the CBR and resilient modulus are $1.46 \pm 0.02$ and $1.16 \pm 0.03$ times those of specimens prepared by the static pressure compaction method, respectively. The ratio of soil to rock, followed by the maximum particle size, lead obvious influences on the properties of soil-rock mixtures. Moreover, the results show that the CBR and resilient modulus of soil-rock mixtures prepared by vibration compaction method have a correlation of $86.9 \%$ and $89.1 \%$ with the field tests, respectively, which is higher than the static pressure compaction method.
\end{abstract}

Keywords: soil-rock mixtures; vibration compaction method; static pressure compaction method; compaction characteristic; CBR; resilient modulus

\section{Introduction}

With the construction of highways in the hilly areas of western China, soil-rock mixtures (SRM) after blasting or excavation has gradually used as the main filler of highway subgrades. SRM is composed of coarse rocks and fine soils with a certain gradation, and possesses better water permeability, higher strength and compactness than soil [1]. However, the compaction and mechanical properties of SRM are complicated due to large difference in particle size and uneven gradation [2-5]. Therefore, a lot of research on the influencing factors of SRM road performance has been performed. Kong discovered the compaction density of SRM is related to the mass ratio of soil to rock and the gradation through large-scale compaction tests [6]. Yang et al. used the indoor large-scale direct shear test and PFC discrete element numerical simulation to reveal that the strength of the 
rock has a significant influence on the shear characteristics of the SRM [7]. Wang divided SRM into the multi-soil type and multi-rock type by a large number of field test data and established a model for evaluating the compaction quality of the two kinds of SRM [8]. Tu et al. studied the particle crushing characteristics and shear strength characteristics of soil-rock mixtures from macro and meso-level perspectives and revealed the influence of rock content and particle crushing on the shear strength characteristics of SRM [9]. Robert et al. proposed a laboratory compaction standard of SRM [10]. Wang et al. developed a large-scale compaction instrument capable of compacting SRM with a maximum particle size of $120 \mathrm{~mm}$ and studied the factors affecting the maximum dry density of SRM [11]. Zhou et al. investigated the effect of freeze-thaw cycles on the mechanical properties of SRM [12]. All the above research discovered that density is an important factor affecting the mechanical properties of SRM, which depends on the maximum dry density measured in the laboratory and the compactness measured in the field. Moreover, the maximum dry density is related to the laboratory compaction methods [13-16].

Currently, the maximum dry density of subgrade soils, granules, and some materials stabilized with inorganic binders is measured mainly by compaction method, which is the static pressure compaction method (SPCM), the shaking table method (STM) and the surface compaction method (SCM). SPCM is the most widely used all over the world, and is applied to the materials with particle sizes of no more than $40 \mathrm{~mm}$. Although the SPCM has been used for road subgrade geotechnical tests for a long time, it still has shortcomings: (1) the standard laboratory density measured by SPCM is low, due to the fact that the compaction energy and method of SPCM are proposed based on the 12-15 tons compaction roller commonly used in the late 1980s and are inconsistent with modern heavy-duty compacting rollers of more than 20 tons; and (2) the SPCM is unsuitable for non-adhesive and free-draining soil, such as sand and pebble. To better simulate the vibration compaction roller, the shaking table method (STM) was developed. Compared with the SPCM, the STM applies vibration force, which can simulate the vibration compaction effect of roller. Therefore, the density of the prepared specimens is improved by $3-5 \%$, and the elastic modulus is improved by approximately $20 \%$ [17]. However, the STM applies vibration from the bottom to the top, which is opposite that of the roller in the field. Additionally, due to the limited power of the vibration table, the vibration of heavier specimens cannot be realized. To overcome the limitation of the vibration power, the SCM was developed, which can better simulate the vibration characteristics of the on-site vibratory roller. However, the vibrator motor on the vibratory roller cannot simulate the compaction conditions of multiple compaction parameters in the field, for it has only one frequency and amplitude. The SCM is suitable for non-adhesive, free-draining, and coarse-grained soil with maximum particle diameters of less than $60 \mathrm{~mm}$ [18]. In addition, to simulate on-site compaction and obtain information on the compaction process of the asphalt mixture, the Strategic Highway Research Program proposed superior gyratory compaction methods (SGC). This method is mainly for asphalt mixtures, and it is applied rarely in subgrade and cement stabilized macadam base $[19,20]$.

To overcome the shortcomings of these traditional methods, Chinese scholars have developed the laboratory vibration compaction method (VCM). The VCM is performed via the vertical vibration test equipment (VVTE), which can simulate the vibration and oscillation of a vibratory roller [21,22]. The VCM is mainly used for the semi-rigid mixtures, such as cement stabilized gravel. Previous studies showed that the semi-rigid mixtures prepared by VCM has larger density, superior mechanical properties, and better durability than those of mixtures prepared by SPCM [23-25]. The mechanical properties ratio between the laboratory cement-stabilized macadam specimen prepared by the VCM and the on-site specimens is over $90 \%$ [26]. In addition, Zvonaric et al. used laboratory vibration compaction methods to study the factors affecting the compaction and strength characteristics of unbonded and cement-bound mixtures and proposed that the compaction and strength characteristics are significantly different due to different compaction methods [27]. The VCM is also used to prepare unbound graded aggregates. Compared with the SPCM, the 
unbound graded aggregates prepared by VCM have better mechanical properties [28]. The VCM was gradually applied to the asphalt surface in recent years for its advantages. Oliveira et al. proposed a laboratory VCM that better simulates the conditions of the on-site asphalt mixture [29]. Jiang et al. used the VCM and Marshall methods to design asphalt mixtures and evaluate their road performance, which indicates that the asphalt mixture laboratory prepared by VCM is better than that of the mixture prepared by Marshall method [30,31]. In recent years, the VCM has been also promoted to the subgrade soils, such as loess [32,33], sandy soil [34] and saline soil [35]. These studies illustrate the applicability of the VCM for soil, but whether this method is applicable to SRM has not been studied.

To address this gap in research, this study aimed to: (1) determine the reasonable parameters of VCM for SRM through laboratory experiments and field tests and further compare VCM with the traditional method SPCM, which is most widely used; (2) investigate the compaction characteristic, resilient modulus, and CBR of SRM prepared by the VCM; and (3) carry out on-site investigations to verify the laboratory results.

\section{Materials and Testing Methods}

\subsection{Soil-Rock Materials}

SRM was taken from the excavation site of Wuyi County, Zhejiang Province, as shown in Figure 1. The particle composition of SRM is shown in Table 1. SRM is usually divided into soil and rock. Generally speaking, particles smaller than $5 \mathrm{~mm}$ in diameter are considered soil, and those larger than $5 \mathrm{~mm}$ are considered rock [36]. The soil-rock ratio is the mass ratio of soil to rock. The properties of soil separated from the experimental SRM are presented in Table 2. It can be seen from the uniformity coefficient and coefficient of curvature the soil is a kind of cohesive soil.

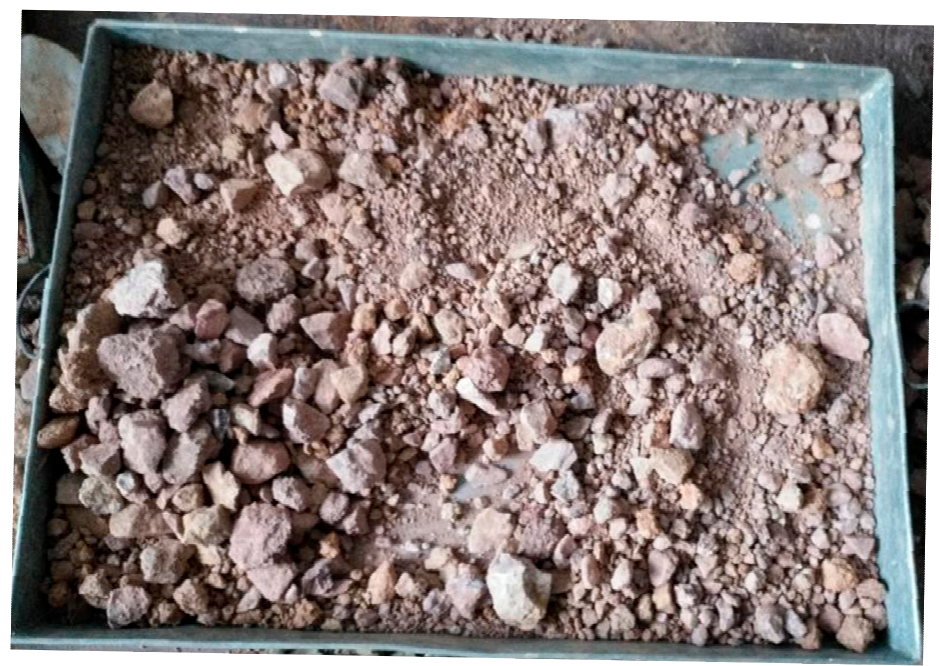

Figure 1. SRM used in experiments.

Table 1. Particle composition of SRM.

\begin{tabular}{cccccccccc}
\hline Sieve Size $(\mathbf{m m})$ & $\mathbf{4 0}$ & $\mathbf{2 0}$ & $\mathbf{1 0}$ & $\mathbf{5}$ & $\mathbf{2}$ & $\mathbf{1}$ & $\mathbf{0 . 5}$ & $\mathbf{0 . 2 5}$ & $\mathbf{0 . 0 7 5}$ \\
\hline Passing rate $(\%)$ & 100 & 89.5 & 73.2 & 54.5 & 29.2 & 21.7 & 11.0 & 5.1 & 1.7 \\
\hline
\end{tabular}

Table 2. Soil properties.

\begin{tabular}{ccccc}
\hline Uniformity Coefficient & Coefficient of Curvature & Liquid Limit (\%) & Plastic Limit (\%) & Plasticity Index \\
\hline 13.8 & 1.4 & 30 & 21 & 9 \\
\hline
\end{tabular}




\subsection{Testing Methods}

\subsubsection{CBR Test}

SPCM and VTM were used to form test pieces, respectively, and the test pieces were soaked in water for 4 days and nights, and then the penetration test was performed on the specimens to obtain the relationship curve between unit pressure and penetration amount. Generally, the ratio of the unit pressure when the penetration amount is $2.5 \mathrm{~mm}$ to the standard pressure is used as the CBR. At the same time, the CBR when the penetration amount is $5 \mathrm{~mm}$ was also calculated. If the CBR when the penetration amount is $5 \mathrm{~mm}$ was greater than the CBR when the penetration amount is $5 \mathrm{~mm}$, then the test was redone, and if the result was still the same, the CBR at $5 \mathrm{~mm}$ was used.

\subsubsection{Resilient Modulus Test}

The test procedure of the resilience modulus is as follows: pre-compress the specimens formed by the SPCM and VTM methods with the load-bearing plate, and pre-compress 1-2 times for 1 min each time. Divide the predetermined maximum pressure into 4-6 parts, as the loading pressure of each stage, load and unload stage by stage. The time for each loading and unloading is $1 \mathrm{~min}$. Record the displacement after each level of loading and unloading, calculate the rebound deformation under each level of load, and then calculate the resilience modulus under each level of load according to Equation (1).

$$
E=\frac{\pi p D}{4 l}\left(1-\mu^{2}\right)
$$

where:

$P$ is pressure on the bearing plate;

$D$ is the bearing plate;

$l$ is rebound deformation corresponding to pressure;

and $\mu$ is poisson's ratio.

\section{Development of the VCM for SRM}

\subsection{Determination of Work Parameters of the VCM for SRM}

To fully simulate the rolling effect of modern heavy vibratory rollers, Chinese researchers have developed a laboratory vibratory compactor based on the principle of directional vibratory rollers. As shown in Figure 2, the vibratory compactor is mainly composed of three parts: the control platform, the rotating device and the vibration system. The vibration system is the most important part of the vibratory compactor, which is mainly composed of the frame, the vibrating entity and the vibrating hammer. Among them, the vibration entity is designed to imitate the vibration device of a vibratory roller, and is divided into vibration exciter, boarding system, and getting off system. The exciter is the core component of the vibration system. It consists of two parallel vibration shafts and a set of eccentric blocks mounted on them. The eccentric blocks on the two vibration shafts are arranged symmetrically. The eccentric blocks on each axis consist of a fixed eccentric block and a movable eccentric block. Composition to achieve the purpose of adjustable eccentricity. The boarding and getting off systems are connected by the vibration damping block, and the getting off system receives regular vibration through the restraining effect of the boarding system [29]. 


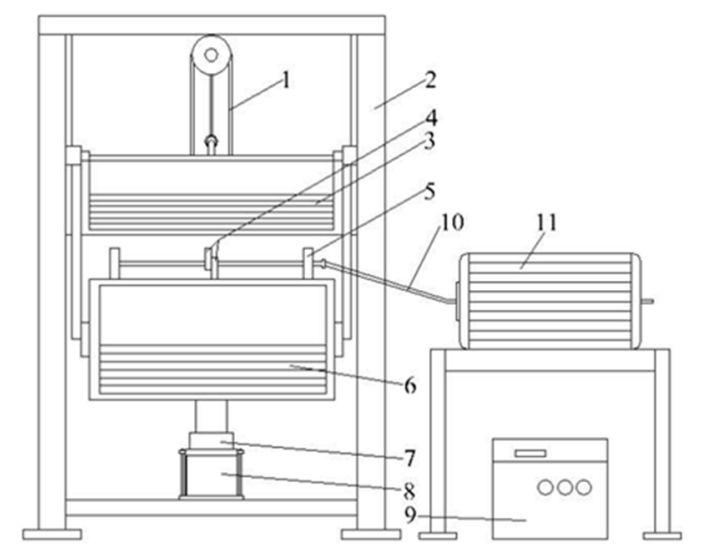

1-Lifting system 2-Frame 3-Boarding system 4-Eccentric block

5-Rotary axis 6-Getting off system 7-Vibrating hammer

8-Trial mode 9-Control system 10-Rotary axis 11-Motor

Figure 2. Vertical Vibratory Compactor's Construction Schematic [25].

There are four key parameters affecting the compaction effect, namely vibration frequency, exciting force, static pressure, and compaction time. The theoretical analysis, laboratory experiments, and field testing were conducted to determine the reasonable parameters, including:

Step 1: First, the soil-rock mixture was divided into two parts with a $5 \mathrm{~mm}$ sieve. Particles smaller than $5 \mathrm{~mm}$ in diameter are considered soil, and those larger than $5 \mathrm{~mm}$ are considered rock. Five soil-rock materials with different soil-rock ratios $(r)$ were mixed for experiments, namely 70:30, 60:40, 50:50, 40:60, and 30:70.

Step 2: The vibration frequency was set as $20 \mathrm{~Hz}, 25 \mathrm{~Hz}, 30 \mathrm{~Hz}, 35 \mathrm{~Hz}$, and $40 \mathrm{~Hz}$, and then the maximum dry density of SRM was tested under different vibration frequencies. The frequency with the maximum density was determined as the optimal frequency.

Step 3: Different exciting forces were obtained by adjusting the angle of the eccentric block, namely $1.5 \mathrm{kN}, 3.8 \mathrm{kN}, 4.6 \mathrm{kN}, 6.2 \mathrm{kN}, 5.3 \mathrm{kN}, 6.0 \mathrm{kN}, 7.5 \mathrm{kN}, 9.0 \mathrm{kN}$, and $11.0 \mathrm{kN}$, respectively. The maximum dry density of SRM under different exciting forces was tested by the VCM. The optimal exciting force was proposed based on the relationship between the density and exciting force.

Step 4: Different static pressures were obtained by adjusting the number of counterweights, namely $122.7 \mathrm{kPa}, 139.9 \mathrm{kPa}, 154.0 \mathrm{kPa}, 163.2 \mathrm{kPa}$, and $169.4 \mathrm{kPa}$, respectively. The maximum dry density of SRM under different static pressure was tested. The optimal static pressure was recommended according to the results.

Step 5: VCM was used to perform indoor vibration compaction at different times ( $35 \mathrm{~s}, 45 \mathrm{~s}, 55 \mathrm{~s}, 65 \mathrm{~s}$, and $75 \mathrm{~s}$ ), and the results were compared with the density of the SMR subgrade after on-site compaction. The recommended vibration compaction time was determined as the time when the indoor density reaches the on-site density. A $20 \mathrm{t}$ single-drum vibratory roller was used for on-site compaction, and the rolling process was follows: static pressing 1 pass and then vibrating pressing 6 passes.

\subsubsection{Vibration Frequency}

The vibration frequency $f$ is the rotational frequency of the eccentric block, as in Equation (2) [37].

$$
\omega=2 \pi f
$$

where $\omega$ is the speed of the vibration exciter, $\mathrm{rad} / \mathrm{min}$.

The vibrating hammer can vibrate up or down under the action of the transfer of the eccentric block, and it applies a periodic vibration force to the material to be compacted. The frequency is related to the natural frequency of the material to be compacted. The vibration frequency was varied to compact SRM with different soil-rock ratios (r), and 
the maximum dry density was obtained. The results were shown in Figure 3. It can be seen from the results that the maximum dry density of SRM increases rapidly with the increasing vibration frequency when the frequency is rather small, achieves the maximum peak when the frequency is $25 \mathrm{~Hz}$, and then gradually decreases to a small valley when the frequency is $28 \mathrm{~Hz}$. Then, it increases to a second peak at $35 \mathrm{~Hz}$ and, finally, quickly decreases. Previous research showed that when the vibration frequency of the road roller is $\sqrt{2}$ times of natural frequency of the compacted materials [38], resonance easily occurs, and the compaction effect is best. The natural frequency of SRM is approximately $17 \sim 20 \mathrm{~Hz}$, and thus the corresponding optimal vibration frequency of the equipment for SRM is $24 \sim 28 \mathrm{~Hz}$. When the vibration frequency is small, the compaction effect increases with the frequency, and the maximum dry density becomes larger. When the vibration frequency exceeds $28 \mathrm{~Hz}$, the difference between the vibration frequency and the natural frequency of SRM is large, and the compaction effect is weakened. In summary, in order to achieve higher maximum dry density, the vibration frequency is recommended as $25 \mathrm{~Hz}$ for SRM.

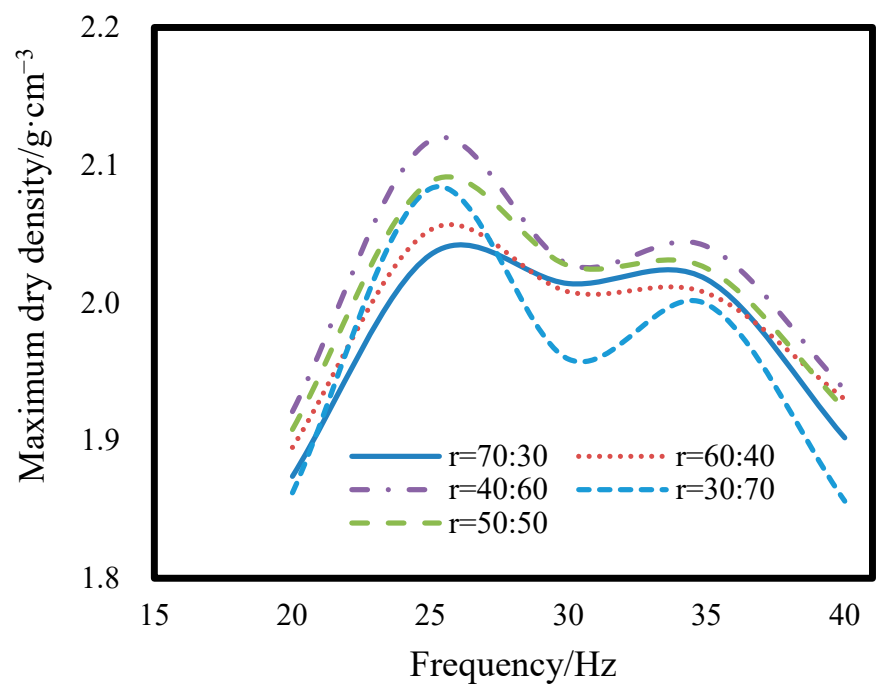

Figure 3. Maximum dry density at different frequencies.

\subsubsection{Exciting Force}

The exciting force $F_{0}$ is formed by the centrifugal force of the eccentric blocks rotating at a high speed, which is related to the static eccentricity $M_{e}$ and the speed of the vibration exciter, as in Equation (3) [37]. The exciting force is a key factor affecting the interaction force between the particles of the compacted material, which, in turn, influences the effect of compaction.

$$
F_{0}=M_{e} \omega^{2}=m_{d} A_{0}(2 \pi f)^{2}
$$

where:

$m_{d}$ is the quality of vibrating system, $\mathrm{kg}$;

and $A_{0}$ is the vibrating amplitude, $\mathrm{mm}$.

It can be known from Equation (3) that there is a power function relation between the exciting force and the frequency. However, the high frequency not only reduces the vibration force of the vibrometer on the compacted material but can also damage the machine.

Different exciting forces can be obtained by adjusting the angle of the eccentric block. The maximum dry densities of SRM under different exciting forces were shown in Figure 4. It can be seen from Figure 4 that the maximum dry density of SRM increases rapidly with increasing exciting force when the exciting force is small and increases gradually as the exciting force further increases. When the exciting force exceeds $5.0 \mathrm{kN}$, the increase in maximum dry density is extremely gentle. A large exciting force does not mean that the compaction effect is good. Only the appropriate exciting force with the correct amplitude 
and frequency can achieve a better compaction effect. In general, the larger the angle of the eccentric block, the larger the amplitude, which not only affects the service life of the device but also causes the surface of the specimens to be uneven. Through experiments, it is found that when the angle of the eccentric block is $0 \sim 30^{\circ}$, the amplitude is within the optimal range of $1.25 \pm 0.05 \mathrm{~mm}$, the surface of the specimens is flat, and the compaction effect is well guaranteed. Therefore, the angle of the eccentric block is recommended as zero, and the corresponding exciting force is determined as $5.3 \mathrm{kN}$.

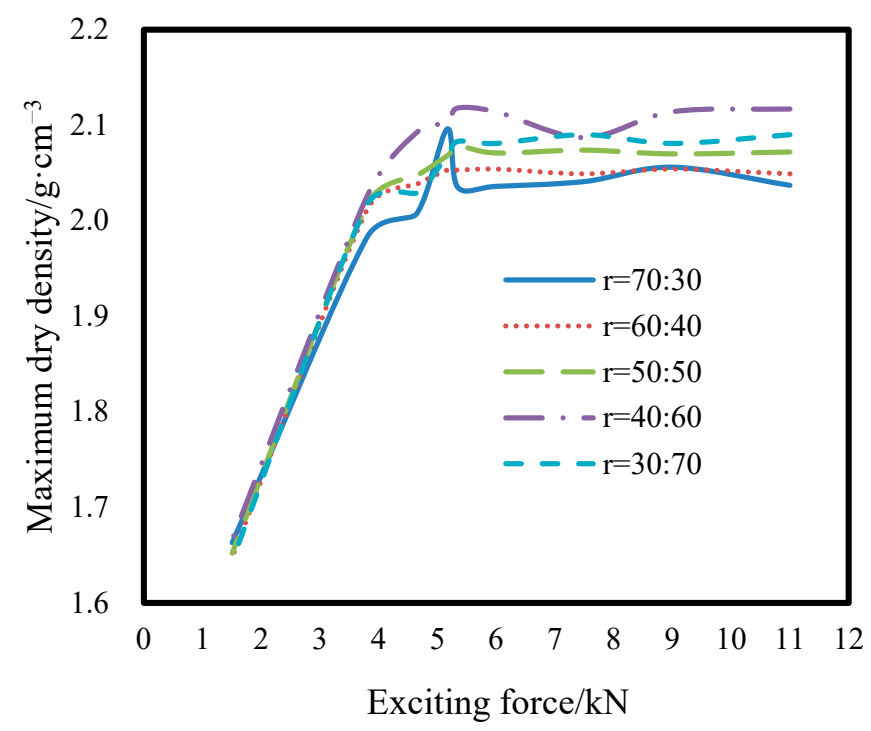

Figure 4. Maximum dry density of SRM under different exciting forces.

\subsubsection{Static Pressure}

The static surface pressure is mainly from the upper system, the nether system, the pressure head, and the clump weight. To increase the vibration force on the material to be compacted, the quality of the nether system is selected to be lower. To increase the impact energy of the material to be compacted, it is desirable to select a nether system with a higher quality.

Different static surface pressures can be obtained by adjusting the number of clump weights [37]. The maximum dry densities of SRM under different static surface pressures are shown in Figure 5. It can be seen from Figure 5 that the pattern of maximum dry density of SRM is shown as a convex type of parabola with the increasing static pressure. A peak occurs at the weights of S4X7 and S5X9 (S4X7 represents four and seven clump weights, respectively, on the upper system and nether system). At the same time, it is found during the test that the vibratory compactor shakes sharply when the counterweight is small. As the number of clump weights increases, the body of the vibratory compactor jumps smoothly and is in a stable working state. If the number of clump weights or static surface pressures is too large, it is difficult for the nether system to jump, and the decrease in amplitude is too large, resulting in poor contact between the pressure head and the specimens. For comprehensive consideration, the recommended weight is S4X7 or S5X9, and the recommended static surface pressure is $154.0 \sim 163.2 \mathrm{kPa}$. 


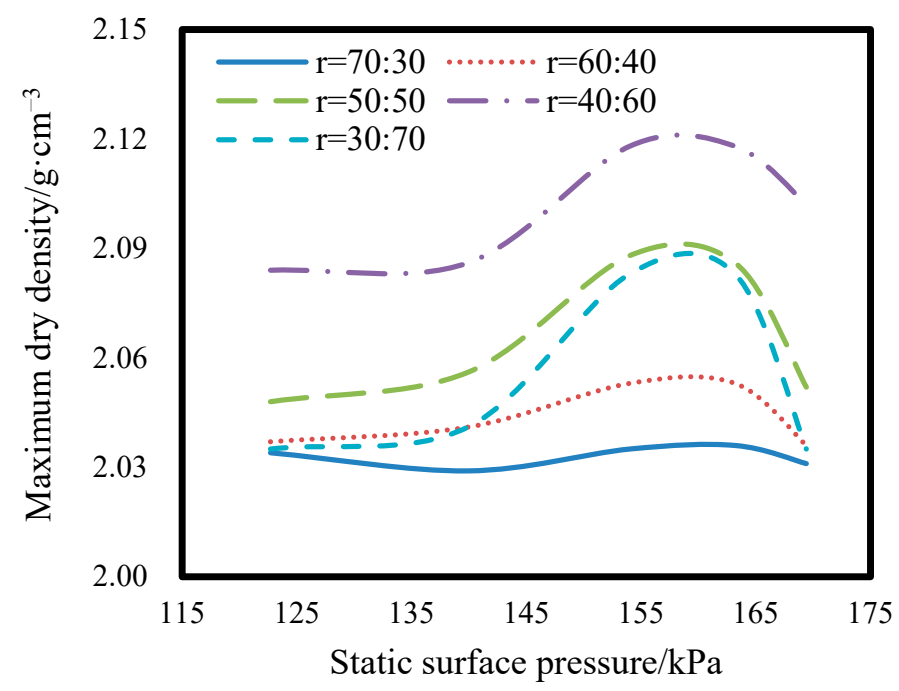

Figure 5. Maximum dry density of SRM under different static surface pressures.

\subsubsection{Compaction Time}

To simulate the compaction characteristics of SRM at the construction site, it is necessary to determine a reasonable compaction time. The vibration time is closely related to the compaction energy. The longer the time is, the greater the compaction energy and the better the compaction effect. When the compaction of SRM increases to a certain extent, the material tends to be in close contact, causing friction between the particles. Most of the compaction energy is converted into heat energy, and the effect of increasing is poor when the compaction time is prolonged. Therefore, it is necessary to determine a reasonable vibration time, and the dry density obtained in the laboratory is basically consistent with the dry density under the representative rolling process in the field. SRM at the construction site of the test section was obtained, and the VCM was used to test the relationship between the dry density and the laboratory vibration compaction time. The results are shown in Figure 6.

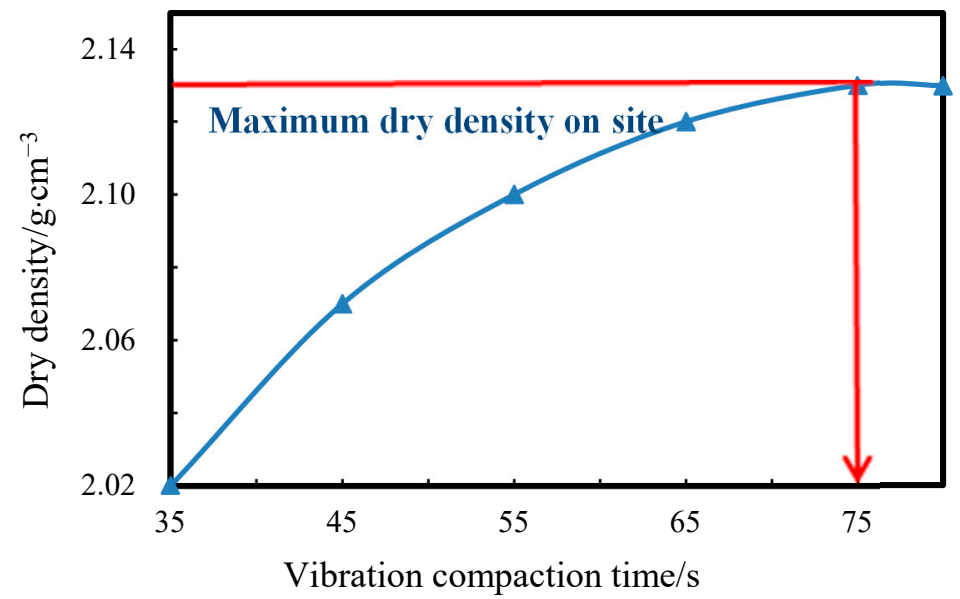

Figure 6. Relationship between vibration time and on-site dry density.

It can be seen from the results that the dry density of SRM increases first with the increase in the vibration time and then gradually stabilizes. If the maximum dry density of SRM is equal to the dry density at the site, then the vibration compaction time of SRM is $75 \mathrm{~s}$. Therefore, it is determined that the laboratory vibration compaction time of SRM is $75 \mathrm{~s}$. To facilitate the control of the compaction degree at the construction site, the relationship between the compaction degree and the vibration compaction time was studied in the 
laboratory. The vibration time of specimens required for different compaction degree were presented in Figure 7 and Table 3.

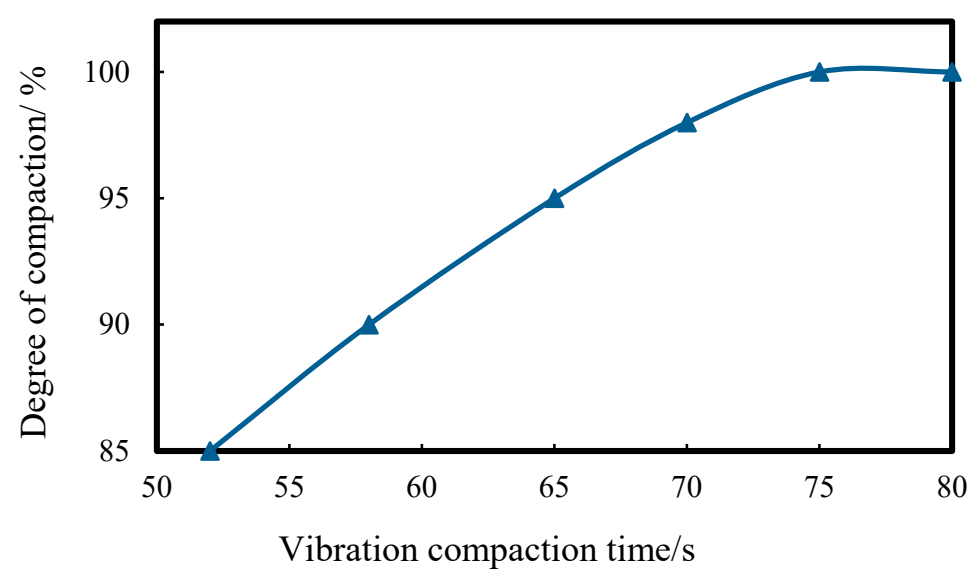

Figure 7. Relationship between vibration time and compaction degree.

Table 3. Compaction time required for different degrees of compaction.

\begin{tabular}{ccccccc}
\hline K (\%) & $\geq \mathbf{9 6}$ & $\geq \mathbf{9 5}$ & $\geq \mathbf{9 4}$ & $\geq \mathbf{9 3}$ & $\geq \mathbf{9 2}$ & $\geq \mathbf{9 0}$ \\
\hline Vibration time (s) & 67 & 65 & 64 & 62 & 60 & 58 \\
\hline
\end{tabular}

\subsection{Detail Procedures of the Established VCM for SRM}

According to the determined work parameters, the VCM for SRM was proposed, which includes two procedures: determining the maximum dry density and optimum water content, and preparing the specimens.

\subsubsection{Determining the Maximum Dry Density and Optimum Water Content}

The SRM was heated in a constant temperature oven with a temperature of $105^{\circ} \mathrm{C}$ for 4-6 $\mathrm{h}$. Then, five specimens from the same SRM were obtained by the quartering method, and then water was added to each specimen at intervals of $2-3 \%$ water content and mixed uniformly. After a night of curing, the SRM was poured into a $\Phi 150 \mathrm{~mm}$ and $\mathrm{h} 230 \mathrm{~mm}$ mold. The testing molds were fixed on a vibrating compactor and vibrated for $75 \mathrm{~s}$. The parameters of the vibrating compactor were summarized Table 4 according to the above investigations. The height of the prepared specimen was required to be at the range of $115-125 \mathrm{~mm}$. The experiments were completed on five SRMs added with different water wight. Water content-dry density was plotted as an $\mathrm{X}-\mathrm{Y}$ coordinate curve. The peak of the curve in the $\mathrm{Y}$ axis was the maximum dry density of SRM, and the corresponding water content was the optimum water content.

Table 4. Parameters of the vibration compactor.

\begin{tabular}{cccccc}
\hline \multirow{2}{*}{ Frequency (Hz) } & \multirow{2}{*}{ Amplitude (mm) } & \multicolumn{3}{c}{ Working Weight (kg) } & \multirow{2}{*}{ Exciting Force (kN) } \\
\cline { 3 - 5 } & & Upper System & Nether System & Total Weight & \\
\hline 25 & $1.2 \sim 1.3$ & $107.08 \sim 115.01$ & $170.69 \sim 179.33$ & $277.77 \sim 294.34$ & 5.3 \\
\hline
\end{tabular}

\subsubsection{Specimen Preparation}

A cylindrical specimen with $\Phi 150 \mathrm{~mm}$ and h150 $\mathrm{mm}$ was prepared via the VCM. The weight of a specimen was determined by Equation (4), in accordance with the maximum dry density, optimum water content, and compaction degree. The vibration compaction time was determined by Table 3 (see also Figure 7) according to the compaction degree. 


$$
m_{0}=V \times \rho_{d} \times\left(1+w_{o}\right) \times K
$$

where:

$m_{0}$ is the specimen weight, $\mathrm{g}$;

$V$ is the specimen volume, $\mathrm{cm}^{3}$;

$\rho_{d}$ is the maximum dry density, $\mathrm{g} / \mathrm{cm}^{3}$;

$w_{0}$ is the optimum water content, $\%$;

and $K$ is the compaction degree, $\%$.

\subsection{Verification of the VCM}

The compaction characteristic, resilient modulus, CBR, and gradation variation of SRM laboratory prepared by the SPCM and VCM were compared to verify the applicability of the VCM. The detailed procedures of SPCM, CBR, and resilient modulus tests were taken from the Chinese specification of JTG E40-2007 [39]. Three parallel experiments are required in CBR and resilient modulus tests.

\subsubsection{Compaction Characteristics}

The specimens with different mass ratios of soil to rock were produced using the VCM and SPCM, and the results of optimum moisture content and maximum dry density are shown in Figure 8. As shown in Figure 8, the maximum dry density of SRM specimens produced using VCM is $1.021 \pm 0.005$ times that of the specimens produced using SPCM, and the optimum moisture content of the specimens produced using VCM is $0.84 \pm 0.01$ times that of the specimens produced using SPCM. The reason for this result is that, under the impact of vibratory compaction, the compacted granular materials transition from the initial stationary state to the moving state, the interaction between the particles transitions from static friction to dynamic friction or sliding friction, and the particles move relative to each other. The coarse particles are in closer contact, and the fine aggregate fills the voids made by the coarse aggregate; at the same time, under the action of the vibration force, the water aggregates to form a water film to provide lubrication for the relative motion between the particles, resulting in the particles being more easily compacted.

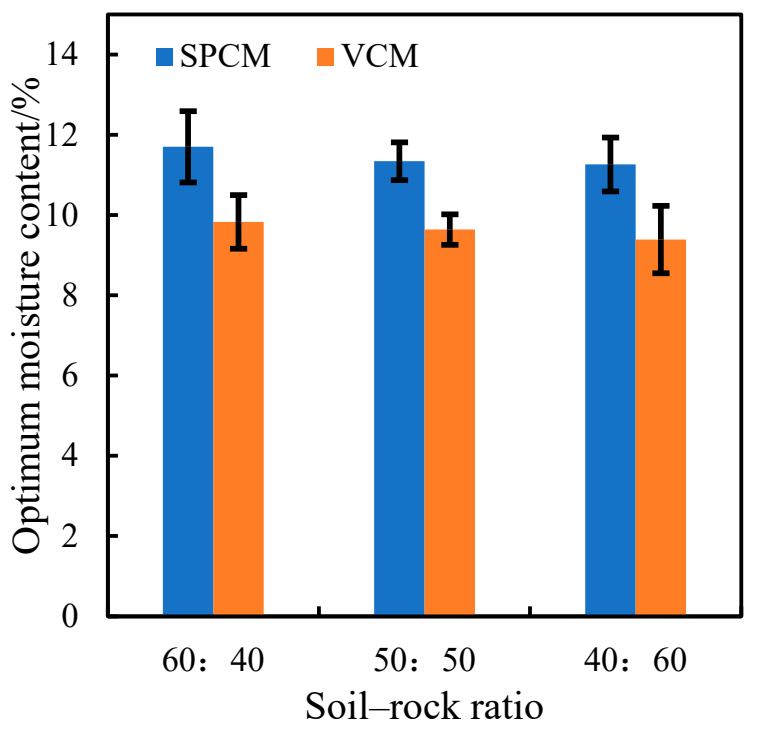

(a) Optimum moisture content

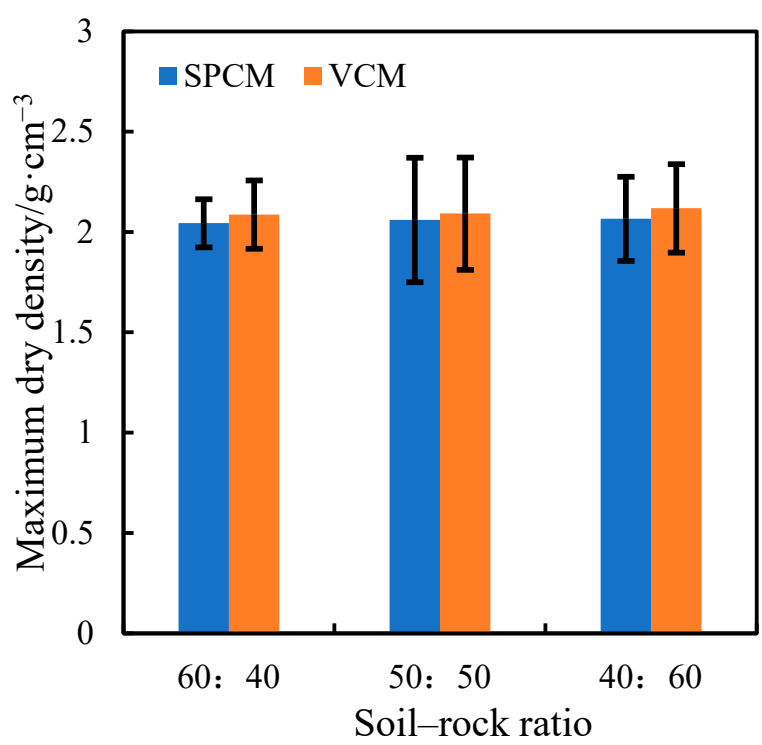

(b) maximum dry density

Figure 8. Comparison of the optimal moisture content and maximum dry density. 


\subsubsection{Resilient Modulus}

The specimens were prepared with the SPCM and VCM for soil-rock ratios of 60:40, 50:50, and 40:60. The resilient modulus of the specimens was measured, and the results are shown in Figure 9. As shown in Figure 9, the resilient modulus of the specimens prepared by the VCM is approximately $1.16 \pm 0.03$ times that of the specimens prepared by the SPCM. This reason is that the mechanical strength of SRM is closely related to the compaction degree.

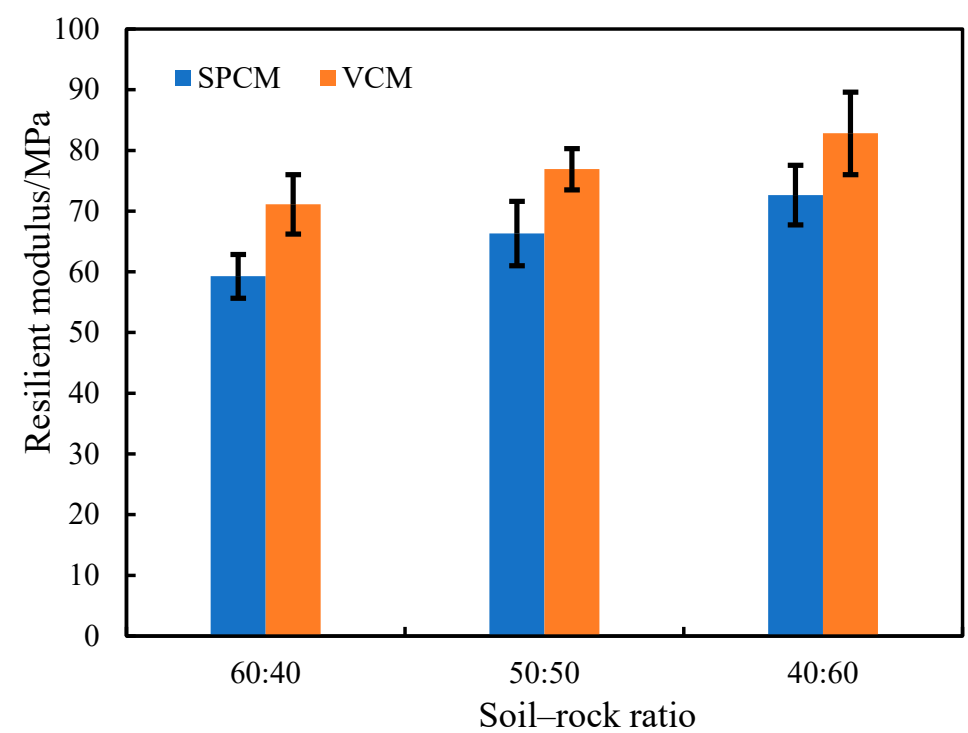

Figure 9. Comparison of the resilient modulus.

\subsection{3. $\mathrm{CBR}$}

The specimens were prepared by the SPCM and VCM and the CBR test of the prepared specimens was carried out. The results are shown in Figure 10. As shown in Figure 10, the CBR of the specimens prepared by the VCM is approximately $1.46 \pm 0.02$ times that of the specimens prepared by the SPCM. The higher the maximum dry density, the less it will be affected by water, the stronger the resistance to unit load penetration, and the greater the CBR.

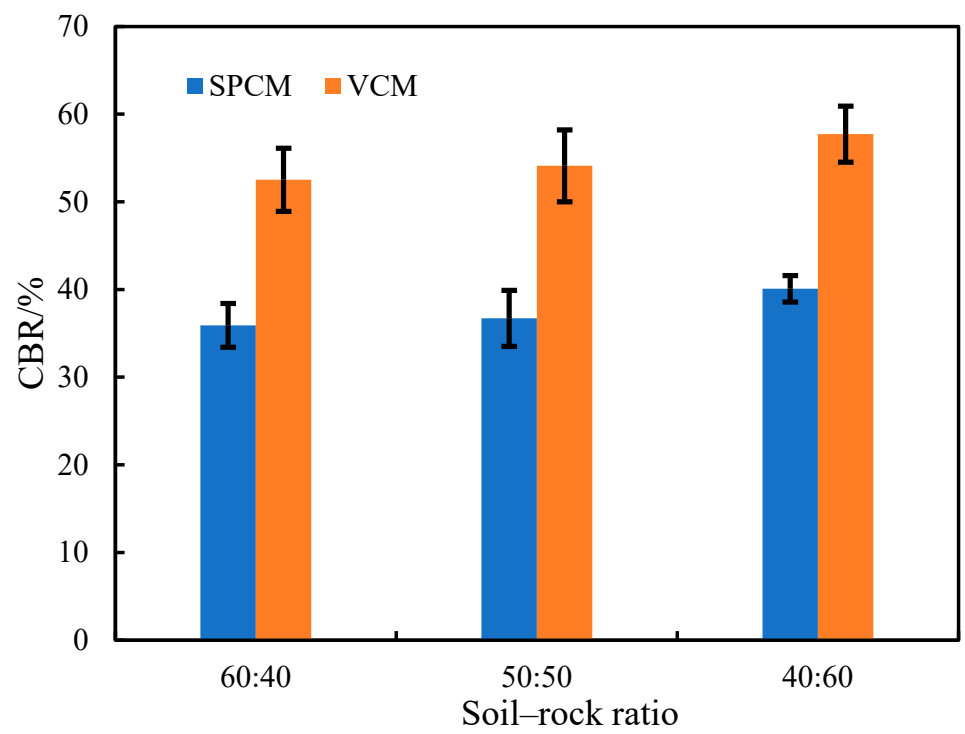

Figure 10. Comparison of test results of the CBR. 


\subsubsection{Gradation Variation}

The gradations of SRMs before compaction and after compaction by the VCM and SPCM were compared to investigate the influence of the different methods on the gradation variation, which was assessed by the deviation coefficient $S$, shown as Equation (5). The larger the $S$, the greater the difference in the pass rate of the same sieve before and after the compaction, which means that the compaction has a more significant crushing effect on the SRM coarse particles.

$$
S=\sqrt{\frac{\left(P_{b, i}-P_{a, i}\right)^{2}}{n-1}}
$$

where:

$P_{b, i}$ is the passing rate at the sieve $i$ before compaction, \%;

$P_{a, i}$ is the passing rate at the sieve $i$ after compaction, \%;

and $n$ is the number of sieves.

Table 5 shows the gradation variation of SRM compacted by the VCM and SPCM. It can be seen from Table 6 that the S of SRM compacted by SPCM was bigger than that of SRM by the VCM, which indicates that the fragmentation on particles caused by the VCM is relatively weak. The reason for this phenomenon is that the particles are prone to becoming crushed to smaller particles as the number of compactions increases. The exciting force of VCM makes the relative movement between the particles is smaller than the SPCM and to achieve a denser effect; thence, the fragmentation of particles is relatively slight [22].

Table 5. Effect of the compaction method on gradation.

\begin{tabular}{|c|c|c|c|c|c|c|c|}
\hline \multirow{2}{*}{ Soil-Rock Ratio } & \multirow{2}{*}{ Method } & \multicolumn{5}{|c|}{ Passing Rate $(\%)$ at Different Sieve Size $(\mathrm{mm})$} & \multirow{2}{*}{$S$} \\
\hline & & 40 & 20 & 10 & 5 & 2 & \\
\hline \multirow{3}{*}{$60: 40$} & Pre-compaction & 100 & 90 & 80 & 60 & 30 & / \\
\hline & SPCM & 100 & 94.2 & 86.8 & 70.2 & 40.4 & 8.31 \\
\hline & VCM & 100 & 91.8 & 82.4 & 64 & 31.3 & 2.58 \\
\hline \multirow{3}{*}{$50: 50$} & Pre-compaction & 100 & 80 & 65 & 50 & 25 & / \\
\hline & SPCM & 100 & 89.3 & 79.7 & 67.9 & 45.1 & 16.02 \\
\hline & VCM & 100 & 85.2 & 72.5 & 56.2 & 31.1 & 6.30 \\
\hline \multirow{3}{*}{$40: 60$} & Pre-compaction & 100 & 70 & 50 & 35 & 15 & / \\
\hline & SPCM & 100 & 85.3 & 63.4 & 57.4 & 29.3 & 16.73 \\
\hline & VCM & 100 & 81.7 & 59.3 & 49.2 & 23.4 & 11.13 \\
\hline
\end{tabular}

Table 6. Correlation of CBR.

\begin{tabular}{ccccccc}
\hline \multirow{2}{*}{ Measuring Point } & \multicolumn{2}{c}{ CBR of Laboratory Specimens (\%) } & \multirow{2}{*}{ CBR of on-Site Subgrade (\%) } & \multicolumn{2}{c}{ Correlation (\%) } \\
\cline { 2 - 3 } & SPCM & VCM & & & SPCM & VCM \\
\hline Measuring point 1 & 35.91 & 52.51 & 60.38 & 59.5 & 87.0 \\
Measuring point 2 & 32.47 & 53.32 & 61.44 & 52.8 & 86.8 \\
\hline
\end{tabular}

\section{Engineering Properties of SRM Prepared by the VCM}

It can be concluded from the above investigations that the VCM does not only simulate the field roller compaction better, but also improves the engineering of SRM. It is very meaningful to promote the application of VCM for SRM. It is fundamental to explore the engineering properties of SRM prepared by the VCM, which are obviously influenced by the soil-rock ratio, maximum particle size, etc.

In order to investigate the influence of soil-rock ratio, nine different ratios of soil to rock were utilized, namely 100:0, 80:20, 70:30, 60:40, 50:50, 40:60, 30:70, 20:80, and 0:100, respectively. For each soil-rock ratio, the soil particles were divided into two groups, 
$\leq 2 \mathrm{~mm}$ and $2-5 \mathrm{~mm}$, and their mass ratio was designated as 55:45. The rock particles were divided into three groups: $20-40 \mathrm{~mm}, 10-20 \mathrm{~mm}$, and 5-10 $\mathrm{mm}$, and their mass ratio was designated as 25:35:40. Three SRMs with the maximum particle size of $40 \mathrm{~mm}, 20 \mathrm{~mm}$, and $10 \mathrm{~mm}$ and with a fixed soil-rock ratio of 50:50 were selected, respectively, to explore the influence of maximum particle size on the engineering properties of SRM.

\subsection{Effect of the Soil-Rock Ratio}

Figure 11 shows the maximum dry density and optimum moisture content of SRM with different ratios of soil to rock produced by the VCM. The results show that the optimum moisture content gradually decreases as the rock content increases, which is caused by the reason that the soil particle has bigger specific surface area than rock particle. The maximum dry density initially increases and then decreases with the increasing the rock content and achieves the peak when the rock content is $60 \%$. This phenomenon can be attributed to the spatial structure of SRM [16]. When the soil ratio in SRM is lager, the rock particles do not mutually contact with each other and are surrounded with soil particles, and a called suspended dense structure appears in SRM. When the soil ratio in SRM is $30-50 \%$, the voids between the rock particles are completely filled by the soil particles, and the rock particles are close to or in contact with each other, finally, a called skeletal dense structure appears in SRM. When the soil ratio in SRM is smaller than $30 \%$ and the voids between the rock particles cannot be completely filled by the soil particles, a called skeletal void structure appears and the density decreases.

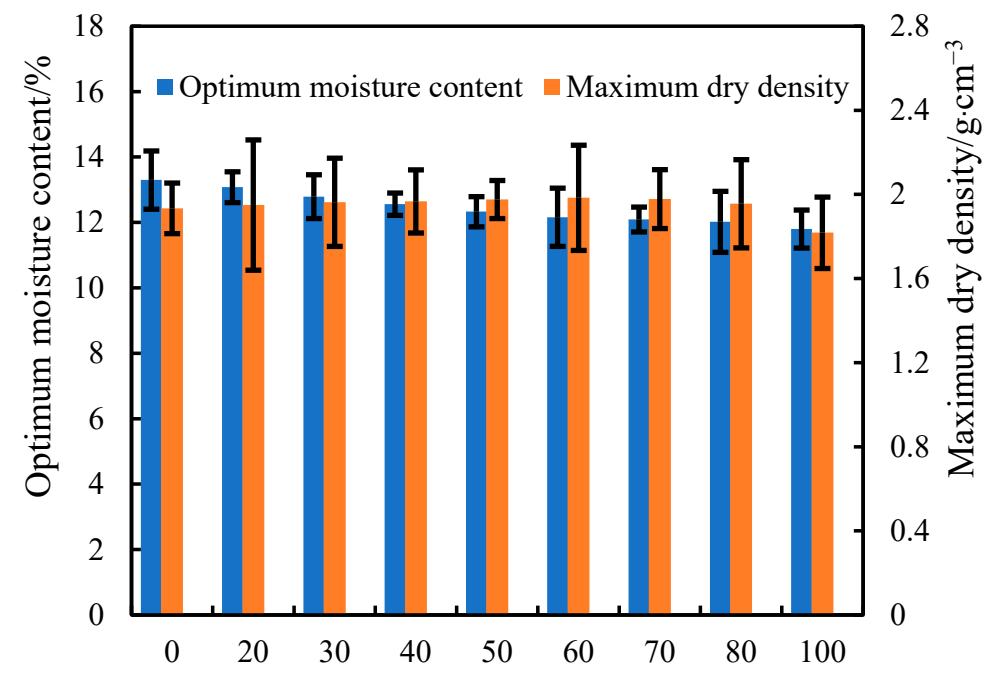

Rock content $/ \%$

Figure 11. Optimum moisture contents and maximum dry densities of SRM with different rock content.

Figure 12 shows the resilient modulus and CBR of SRM produced by the VCM with different soil-rock ratio. It can be seen from Figure 12 that the resilient modulus and CBR of SRM with a rock content of zero is larger that of SRM with a rock content of $20 \%$. When the rock content exceeds $20 \%$, the resilient modulus and CBR of SRM vary in a convex curve with the increasing the rock content and achieve the maximum peak when the rock content is $80 \%$. The mechanical strength of SRM is closely related with the density and structure of SRM. It can be known from Figure 11 that the density of SRM increases initially and then decreases as the rock content increases, and the structure of SRM varies in sequence: suspended dense and skeletal dense. Therefore, the variation in resilient modulus of SRM is influenced by both the density and structure. 


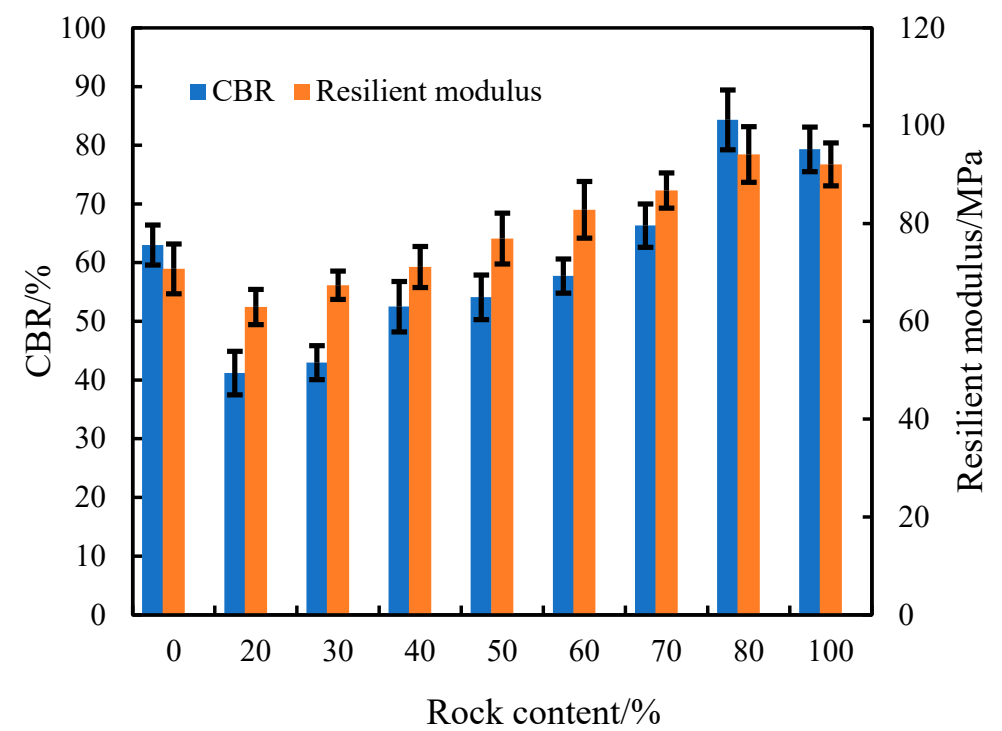

Figure 12. Modulus and CBR of SRM with different rock content.

\subsection{Effect of the Maximum Particle Size}

Figure 13 shows the results of maximum dry density and optimum moisture content of SRM with different maximum particle size produced by the VCM. It can be concluded that the maximum dry density gradually increases with the maximum particle size increasing; on the contrary, the optimum water content gradually decreases. The reason for this phenomenon is that, as the particle size increases, the specific surface area of the mixture decreases relatively, and the water requirement for lubricating the particles also decreases. Meanwhile, the number of rock particles in SRM decreases, meaning that a framework dense structure is easily formed, and the density is increased.

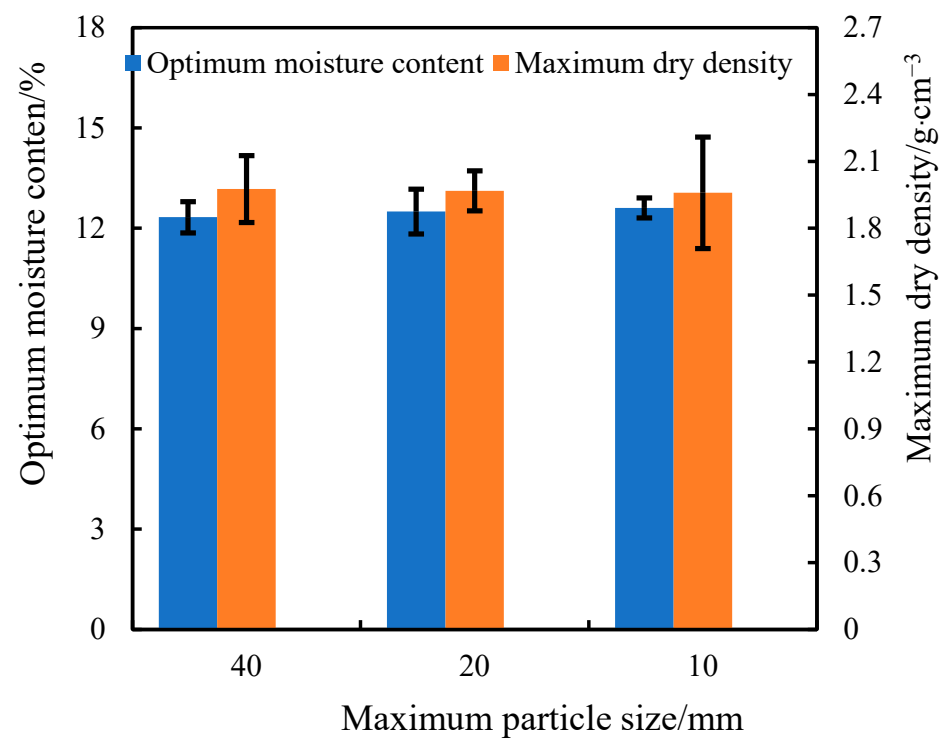

Figure 13. Optimum moisture content and maximum dry density of SRM with different maximum particle size.

Figure 14 shows the results of resilient modulus and CBR of SRM with different maximum particle size produced by the VCM. The same as the density, the resilient modulus and CBR also increase with the increasing of the maximum particle size. 


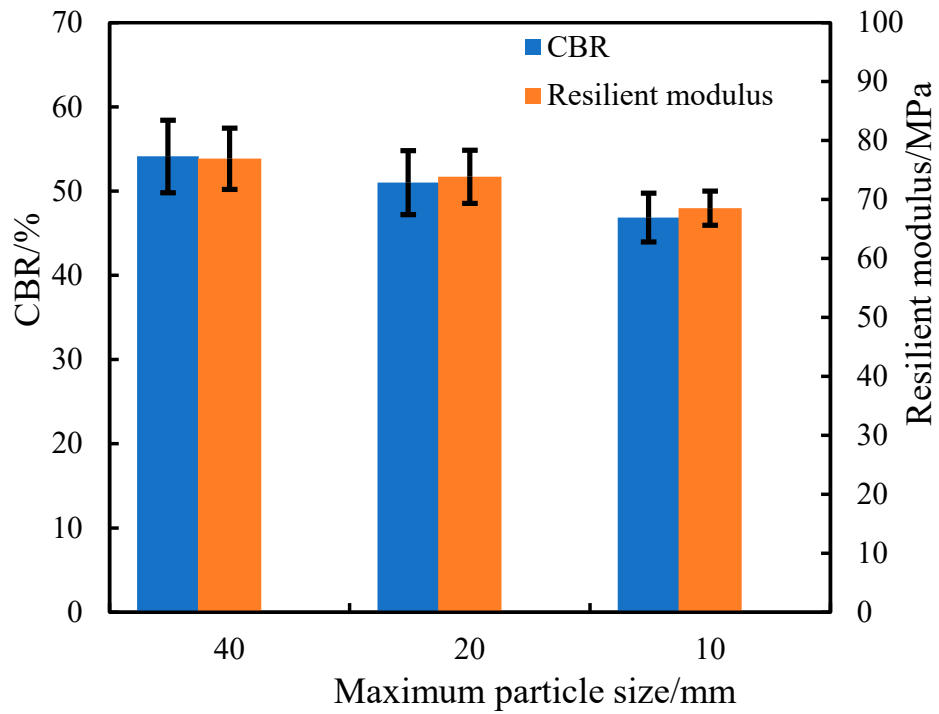

Figure 14. Modulus of SRM with different maximum particles.

\section{Field Application}

A comparison of mechanical properties between the laboratory-prepared SRM and field SRM subgrade was conducted, in order to recommend a more reasonable laboratory compacting method for SRM. The on-site subgrade constructed with SRM was compacted 6-8 times by the vibratory roller. The road for the field measurement was located in the Wuyi section of Wucheng-Wuyi Highway, G235 National Road, Jinhua City, Zhejiang Province, has a total length of $4.472 \mathrm{~km}$, and a design standard of a two-way six-lane first-class highway. The subgrade was constructed with SRM. The resilient modulus and CBR of the subgrade in the field were tested. The required equipment in the test mainly included the loading equipment, jack, dynamometer, rigid bearing plate, and pavement deflectometer. The field test of the CBR is shown in Figures 15 and 16.

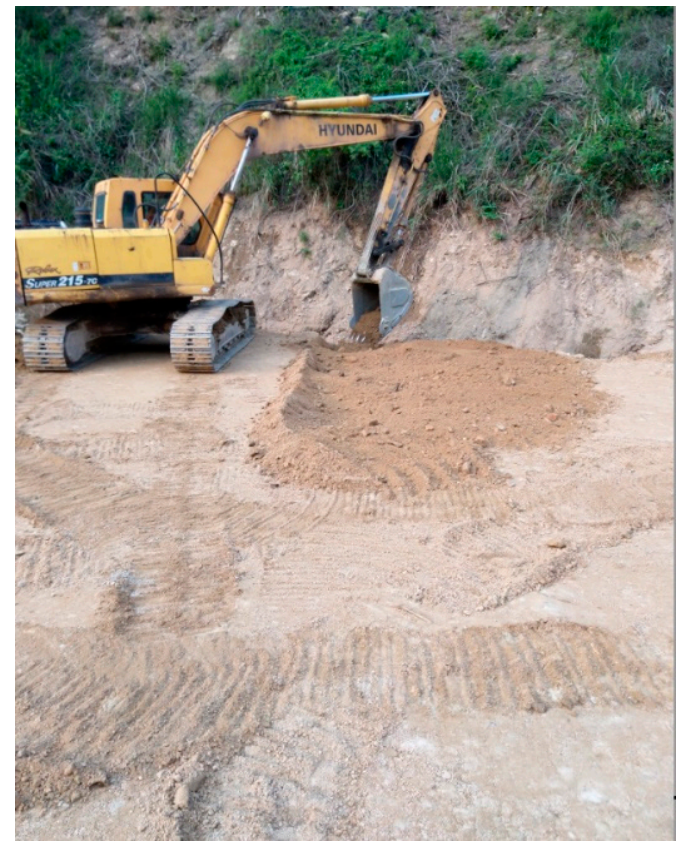

Figure 15. Construction field. 


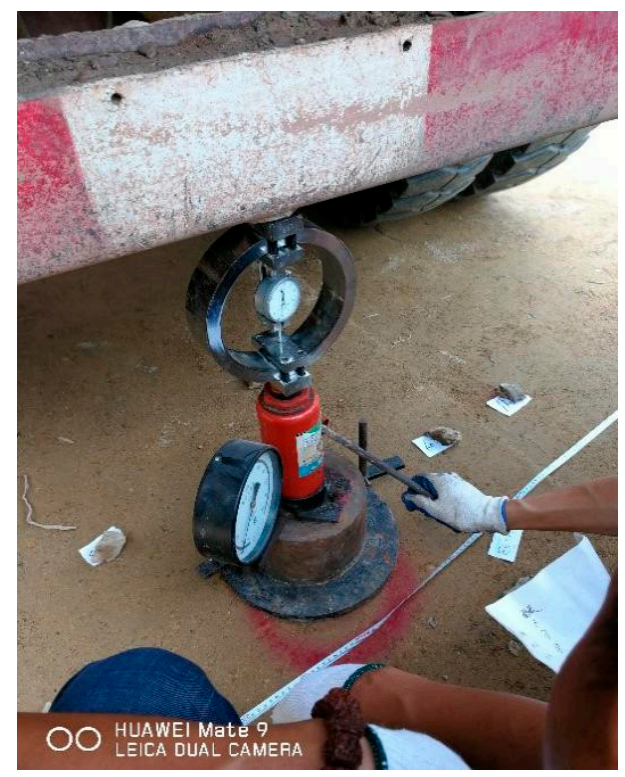

Figure 16. CBR Test in Field.

The measurement results in the field and the laboratory results are shown in Tables 6 and 7. From the results, it can be known that SRM prepared by the VCM have higher densities and mechanical strengths than SRM prepared by the SPCM, which makes the mechanical properties of SRM prepared by the VCM more consistent with the field SRM subgrade. The ratio of the average CBR and resilient modulus of specimens prepared by the SPCM and the field SRM subgrade from two sites is only $56.2 \%$ and $74.2 \%$, respectively. The ratio of the average CBR and resilient modulus of specimens prepared by the VCM and the field SRM subgrade two sites is $86.9 \%$ and $89.1 \%$, respectively. The above results indicate that the VCM has a higher accuracy than the SPCM in evaluating the CBR and resilient modulus of the field SRM subgrade. This phenomenon is explained by the fact that the VCM not only improves the density but also drives the particles to arrange more closely, and further makes the friction between the particles larger. However, the fragmentation of SRM compacted by the SPCM is more critical than that of SMR compacted by the VCM, which negatively influences the mechanical properties of SRM.

Table 7. Correlation of resilient modulus.

\begin{tabular}{|c|c|c|c|c|c|}
\hline \multirow{2}{*}{ Measuring Point } & \multicolumn{2}{|c|}{$\begin{array}{c}\text { Resilient Modulus of } \\
\text { Laboratory Test Piece (MPa) }\end{array}$} & \multirow{2}{*}{$\begin{array}{c}\text { Resilient Modulus of on-Site } \\
\text { Subgrade (MPa) }\end{array}$} & \multicolumn{2}{|c|}{ Correlation (\%) } \\
\hline & SPCM & VCM & & SPCM & VCM \\
\hline Point 1 & 59.27 & 71.12 & 80.32 & 73.8 & 88.5 \\
\hline Point 2 & 61.21 & 73.44 & 82.01 & 74.6 & 89.6 \\
\hline
\end{tabular}

\section{Conclusions}

(1) The vibration frequency, exciting force, and static surface pressure of vibration compactor for SRM is recommended as $25 \mathrm{~Hz}, 5.3 \mathrm{kN}$, and $154.0 \sim 163.2 \mathrm{kPa}$, respectively.

(2) The maximum dry density, optimum moisture content, CBR, and resilient modulus of SRM prepared by the VCM are 1.021 $\pm 0.005,0.84 \pm 0.01,1.46 \pm 0.02$, and $1.16 \pm 0.03$ times those of SRM prepared by the SPCM, respectively. The fragmentation on SRM caused by the VCM is smaller than the SPCM.

(3) Through the laboratory test, the differences in the compaction characteristics, CBR and resilient modulus of SRM and its influencing factors are revealed. The results show that the most obvious influence on the compaction and mechanical properties of SRM 
prepared by the VCM is the soil-rock ratio, followed by the maximum particle size, and gradation basically has no effect.

(4) The CBR and resilient modulus of laboratory-prepared SRM by the VCM have higher correlation with the field measurement than the SPCM. The VCM can evaluate the mechanical properties of the field SRM more precisely than can the SPCM.

(5) To ensure the accuracy of the test, the mold diameter must be no less than four times the maximum particle size of the material. The mold diameter is $150 \mathrm{~mm}$ in VCM, so it is suitable only for SRM with particle sizes less than $40 \mathrm{~mm}$. In future, the authors intend to use numerical simulation methods to investigate the effect of $40-100 \mathrm{~mm}$ particles on the compaction characteristics and mechanical properties of SRM.

Author Contributions: Conceptualization, X.J.; methodology, X.J. and Y.Y.; validation, Y.X. and X.J.; formal analysis, X.J. and Y.X.; investigation, Y.X., X.J. and Y.Y.; data curation, H.L. and Y.X.; writing-original draft preparation, X.J. and Z.C.; writing-review and editing, H.L.; supervision, C.D.; project administration, C.D.; funding acquisition, X.J. All authors have read and agreed to the published version of the manuscript.

Funding: This research was funded by the Sichuan Provincial Transportation Science and Technology under project No. 2019-D-04.

Institutional Review Board Statement: Not applicable.

Informed Consent Statement: Not applicable.

Data Availability Statement: Not applicable.

Conflicts of Interest: The authors declare no conflict of interest.

\section{References}

1. Chai, H.; Chen, Q.; Kong, X.; Dong, Y. Summary of research on construction technology of soil and rock mixture. Rock. Soil. Mech. 2004, 1005-1010. [CrossRef]

2. Liu, L.Q.; Mao, X.S.; Xiao, Y.J.; Wu, Q.; Tang, K.; Liu, F.F. Effect of Rock Particle Content on the Mechanical Behavior of a Soil-Rock Mixture (SRM) via Large-Scale Direct Shear Test. Adv. Civ. Eng. 2019, 2019, 1-16. [CrossRef]

3. Sun, S.R.; Zhu, F.; Wei, J.H.; Wang, W.C.; Le, H.L. Experimental Study on Shear Failure Mechanism and the Identification of Strength Characteristics of the Soil-Rock Mixture. Shock Vib. 2019, 2019, 25. [CrossRef]

4. Salam, S.; Osouli, A.; Tutumluer, E. Crushed Limestone Aggregate Strength Influenced by Gradation, Fines Content, and Dust Ratio. J. Transp. Eng. 2018, 144. [CrossRef]

5. Ren, J.; Yin, C. Investigating mechanical characteristics of aggregate structure for road materials. Int. J. Pavement Eng. 2020, 1-15. [CrossRef]

6. Kong, X. Experimental Study on Compaction Characteristics of Soil and Rock Mixture. Master's Thesis, Chongqing Jiaotong University, Chongqing, China, 2004.

7. Yang, Z.P.; Zhao, Y.L.; Hu, Y.X.; Li, S.Q.; Lei, X.D.; Li, X.Y. Influence of rock strength on shear characteristics of soil-rock mixture. Chin. J. Rock. Mech. Eng. 2021, 40, 814-827. [CrossRef]

8. Wang, J. Research on Rapid Assessment Method of Compaction Quality of Soil-Rock Mixed Subgrade. Master's Thesis, Shanghai Jiaotong University, Shanghai, China, 2007.

9. Tu, Y.L.; Liu, X.R.; Ren, Q.Y.; Chai, H.J.; Wang, J.B.; Yu, J.Y. Study on the influence of rock content and particle crushing on the strength of soil-rock mixture. Rock. Soil. Mech. 2020, 41, 3919-3928. [CrossRef]

10. Torrey, V.; Donaghe, R. Compaction Control of Earth-Rock Mixtures: A New Approach. Geotech. Test. J. 1994, 3, $371-386$.

11. Wang, J.; Gong, H.; Guo, N.N.; Zhou, Y. Large-scale compaction test study of soil-rock mixture. Highway 2021, 66, 297-302.

12. Zhou, Z.; Xing, K.; Yang, H.; Wang, H. Damage mechanism of soil-rock mixture after freeze-thaw cycles. J. Cent. South Univ. 2019, 26, 13-24. [CrossRef]

13. Zhang, Q.; Wang, X.; Zhao, Y.; Liu, L.; Lin, X. 3 D random reconstruction of meso-structure for soil-rock mixture and numerical simulation of its mechanical characteristics by particle flow code. Chin. J. Geotech. 2019, 41, 60-69.

14. Zhao, Y.; Liu, Z. Numerical Experiments on Triaxial Compression Strength of Soil-Rock Mixture. Adv. Civ. Eng. 2019, 2019. [CrossRef]

15. Ji, X.; Li, H.; Xiong, Y.; Hajdu, M.; Shi, Y. Research on vibration test method of soil-rock Mixed subgrade Soil. Highway 2019, 64, 27-32.

16. Ji, X.; Han, B.; Hu, J.; Li, S.; Xiong, Y.; Sun, E. Application of the discrete element method and CT scanning to investigate the compaction characteristics of the soil-rock mixture in the subgrade. Road Mater. Pavement Des. 2020. [CrossRef] 
17. Dai, H.; Fu, Y.; Zhang, Y. Vibration compaction of weak saline soil based on method of shaking table. J. China Fore. Highw. 2014, 34, 64-69.

18. Yan, X. Discussion on Compaction Detection Method of Soil-rock Mixtures Subgrade. J. Highw. Transp. Res. Dev. 2001, 40-42.

19. Arabali, P.; Lee, S.I.; Sebesta, S.; Sakhaeifar, M.S.; Lytton, R.L. Application of Superpave Gyratory Compactor for Laboratory Compaction of Unbound Granular Materials. In Proceedings of the American-Society-of-Civil-Engineers (ASCE) International Conference on Transportation and Development (ICTD), Pittsburgh, PA, USA, 15-18 July 2018.

20. Liu, D.; Li, L. Experiment on Gyratory Compaction of Cement Stabilized Base Course Materials. China J. Highw. Transp. 2019, 32, 118-128.

21. Liu, H.; Cheng, P. Research about different molding methods' effect on the resistance against frost and shrinkage of cement stabilized gravel. In Proceedings of the International Conference on Civil Engineering and Transportation (ICCET 2011), Jinan, China, 14-16 October 2011.

22. Ji, X.; Hou, Y.; Li, X.; Wang, T. Comparison on properties of cement-stabilised gravel prepared by different laboratory compaction methods. Road Mater. Pavement Des. 2019, 20, 991-1003. [CrossRef]

23. Ji, X.P.; Jiang, Y.J.; Liu, Y.J. Evaluation of the mechanical behaviors of cement-stabilized cold recycled mixtures produced by vertical vibration compaction method. Mater. Struct. 2016, 49, 2257-2270. [CrossRef]

24. Deng, C.; Jiang, Y.; Yuan, K.; Tian, T.; Yi, Y. Mechanical properties of vertical vibration compacted lime-fly ash-stabilized macadam material. Constr. Build. Mater. 2020, 251, 119089. [CrossRef]

25. Jiang, Y.; Yuan, K.; Deng, C.; Tian, T. Fatigue Performance of Cement-Stabilized Crushed Gravel Produced Using Vertical Vibration Compaction Method. J. Mater. Civ. Eng. 2020, 32. [CrossRef]

26. Zhang, B. Research on Design Parameters of Cement Stabilized Macadam Based on VTM. Master's Thesis, Chang'an University, Xi'an, China, 2011.

27. Zvonaric, M.; Barisic, I.; Galic, M.; Minazek, K. Influence of Laboratory Compaction Method on Compaction and Strength Characteristics of Unbound and Cement-Bound Mixtures. Appl. Sci. 2021, 11, 4750. [CrossRef]

28. Deng, C.Q.; Jiang, Y.J.; Zhang, Y.; Yi, Y.; Tian, T.; Yuan, K.J.; Fan, J.T. Mechanical properties and influencing factors of verticalvibration compacted unbound graded aggregate materials. Transp. Geotech. 2021, 28, 10. [CrossRef]

29. Oliveira, M.F.; Bessa, I.S.; Vasconcelos, R.R.; Vasconcelos, K.L.; Bernucci, L.L.B. A new approach to laboratory roller compaction method and its influence on surface texture and permanent deformation of asphalt mixtures. Int. J. Pavement Eng. 2021, 1-12. [CrossRef]

30. Jiang, Y.J.; Deng, C.Q.; Xue, J.S.; Chen, Z.J. Investigation into the performance of asphalt mixture designed using different methods. Constr. Build. Mater. 2018, 177, 378-387. [CrossRef]

31. Jiang, Y.J.; Lin, H.W.; Han, Z.C.; Deng, C.Q. Fatigue Properties of Cold-Recycled Emulsified Asphalt Mixtures Fabricated by Different Compaction Methods. Sustainability 2019, 11, 3483. [CrossRef]

32. Sha, A.; Chen, K.; Ma, F. Indoor test on physical-mechanical properties of loess under vibration compaction. J. Chang'an Univ. (Nat. Sci. Ed.) 2008, 28, 1-5. [CrossRef]

33. Jiang, Y.; Yuan, K.; Li, Q.; Deng, C.; Yi, Y.; Zhang, Y.; Xue, J. Comparison of Mechanical Properties of Cement-Stabilized Loess Produced Using Different Compaction Methods. Adv. Mater. Sci. Eng. 2020, 2020. [CrossRef]

34. Nan, B. Study on Indoor Vibratory Compaction of the Subgrade Packing and Settlement Deformation. Master's Thesis, Chang'an University, Xi'an, China, 2014.

35. Chen, Z.; Huang, Z.; Yin, L. Experimental study on pavement performance of improved saline soil mixed with gravel. Subgr. Eng. 2017, 18, 97-100.

36. Zhou, Z.; Zhu, H.; Zhang, Y. Microscopic Analysis of the Structural Strength of Soil-rock mixture. China J. Highw. Transp. 2008, 21, 30-34. [CrossRef]

37. Jing, Y. Study on Vibration Test Methods for Cement Stabilization of Crushd Aggregate; Southeast University: Nanjing, China, 2009.

38. Zhang, H. Research on Compaction Mechanism of Full Hydraulic Single Drum Vibratory Roller. Master's Thesis, Chang'an University, Xi'an, China, 2016.

39. RIOH. Test Methods of Soils for Highway Engineering: JTG E40—2007; China Communications Press: Beijing, China, 2007. 